\title{
SPECIFIC AND RAPID DETECTION OF MICROSPORIDIA IN STOOL SPECIMENS FROM AIDS PATIENTS BY PCR
}

\author{
OMBROUCK C.*, CICERON L.* \& DESPORTES-LIVAGE I.*
}

\section{Summary:}

Two microsporidian species, Enterocytozoon bieneusi and Encephalitozoon intestinalis, are the cause of diarrhoea and wasting syndrome in AIDS patients. A new PCR assay is proposed for the rapid and specific detection of these parasites in stools.

KEY WORDS : AIDS, microsporidia, PCR, stools.

During the last decade, intestinal microsporidia have become recognized as an important cause of opportunistic infections in immunocompromised patients, especially those with AIDS. Two species are the cause of diarrhoea and other gastrointestinal diseases in HIV infected patients: Enterocytozoon bieneusi (Desportes et al., 1985) and Encephalitozoon intestinalis (Hartskeerl et al., 1995). Diagnosis of gastrointestinal microsporidiosis can be made by detecting spores of the parasites in stool specimens with Weber's modified trichrome stain or optical brightening agents such as Uvitex 2B (De Girolami et al., 1995). However the identification of microsporidia to the species level currently depends on the observation of cytological characteristics only viewed with the electron microscope. The specific identification of microsporidia is of importance because E. intestinalis responds to albendazole therapy. Up to this date, no convincing therapy is available for E. bieneusi. Molecular studies have shown that the small-subunit (SSU) rRNA genes of microsporidia shared only limited homology with the SSU rRNA genes of other eukaryotic organisms, pointing out that these sequences may be useful as gene probes in hybridization and polymerase chain reaction (PCR) assays (Weiss et al., 1994). We therefore evaluated the diagnostic value of amplification of microsporidian DNA by PCR with template DNA extracted from stool specimens from HIV-infected patients with and without intestinal microsporidiosis, as confirmed by light-microscopy. Positive controls for PCR were obtained from cultures for E. intestinalis and from spores isolated by flow cytometry for E. bieneusi (Challier et al., 1994).

\footnotetext{
* Unité INSERM 313, CHU Pitié-Salpêtrière, 91, boulevard de l'Hôpital, 75013 Paris.
}

Résumé : DÉTECTION SPÉCIFIQUe ET RAPIDE DES MIĊROSPORIDIES PAR LA PCR DANS les SElles de PATIENTS atTeINTS DE SIDA

Deux microsporidies, Enterocytozoon bieneusi et Encephalitozoon intestinalis, causent la diarrhée et l'amaigrissement de patients atteints de SIDA. Un nouveau test par la PCR permet la détection rapide et spécifique de ces parasites dans les selles.

MOTS CLÉS : SIDA, microsporidie, PCR, selles.

DNA was released from microsporidia by boiling the samples. The PCR reaction was performed under conditions described by Weiss (1994). The primer pair V1 and EB450 was used to amplify DNA from E. bieneusi and the internal 30 mer oligonucleotide EB150 was used to confirm by southern blotting that the amplified fragment was from E. bieneusi. The primer pair V1 and SI500 was used to amplify DNA from E. intestinalis.

In samples containing E. bieneusi, amplification of the predicted $350 \mathrm{bp}$ fragment was indisputable on ethidium stained gels (Fig. 1A). Using an internal oligomer, hybridization was apparent in all of these samples (Fig. 1B). In negative stools no amplification was seen by ethidium staining or detected by hybridization. In addition, primer pair V1 and SI500 amplified a 380 bp fragment from stools infected with E. intestinalis and from cultured parasite but not from uninfected stools. No amplification was seen with E. bieneusi infected stool samples (Fig. 1A). No hybridization was observed when using EB150 the specific probe of E. bieneusi (Fig. 1B).

PCR has already been used by Fedorko (1995) to identify intestinal microsporidia in stools. However, the PCR assay proposed by this author required harsh conditions employing both mechanical and chemical disruption and a laborious 4-day procedure. Comparatively, boiling the samples to release DNA from microsporidia appears to be a simple and time-saving method. Indeed our PCR assay can be performed within one day and its specificity is high since we use two pairs of primers selective of each intestinal species. These qualities indicate that the PCR procedure proposed herein for the species-specific detection of 


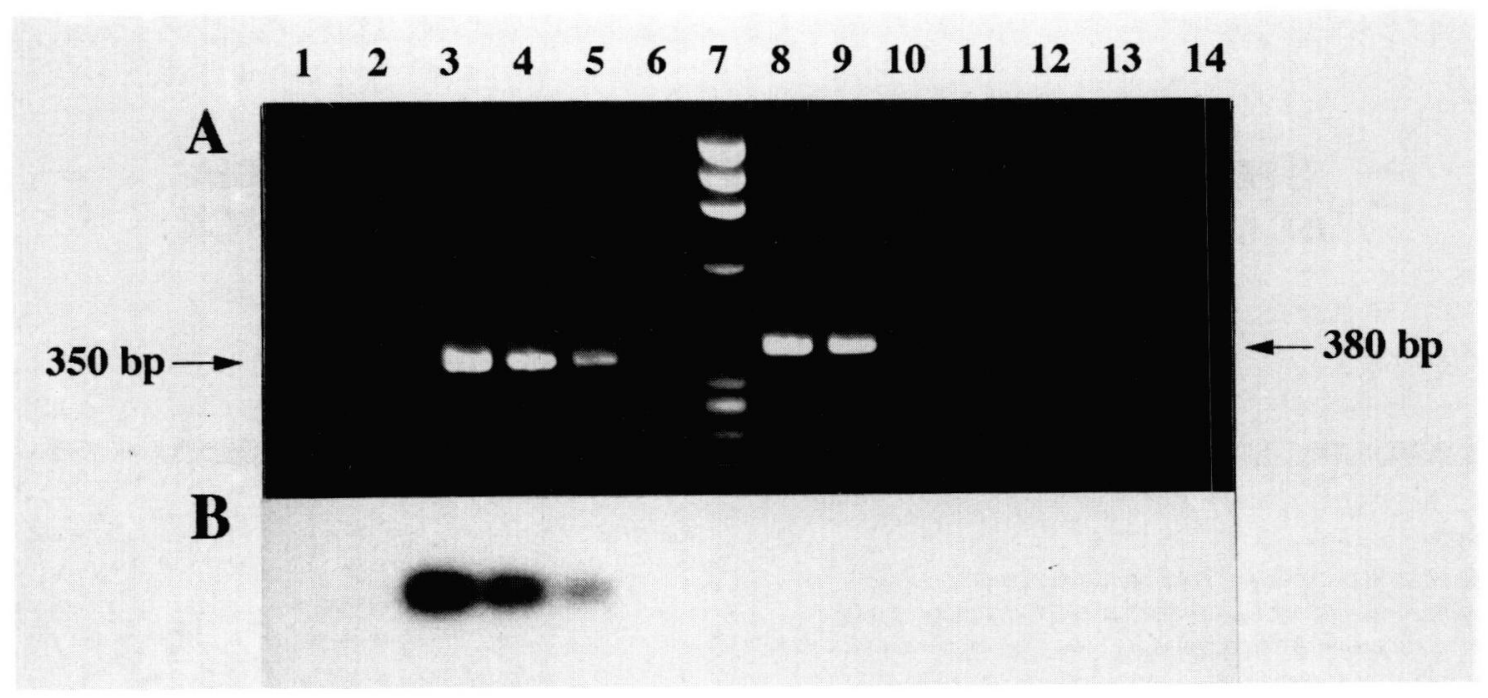

Fig. 1. - Analysis of PCR products by agarose gel electrophoresis. A) Analysis by agarose gel electrophoresis. B) Southern blot and hybridization with EB150 probe to confirm that primer set V1/EB450 amplifies SSU-rRNA gene from E. bieneusi.

Lanes 1-6: PCR was based on the amplification of a 350 bp fragment of the SSU-rRNA of E. bieneusi; 1-2: stools with no known microsporidia; 3-4: E. bieneusi from stool; 5: E. bieneusi isolated by cytometry; 6: E. intestinalis from culture.

Lane 7: DNA fragments of the Hae III-digested $\Phi$ X174. Lanes 8-14: PCR was based on the amplification of a 380 bp fragment of the SSUrRNA of E. intestinalis; 8: E. intestinalis from culture; 9: E. intestinalis from stool; 10: E. bieneusi from stool; 11: E. bieneusi isolated by cytometry; 12-13: stools with no known microsporidia; 14: control.

intestinal microsporidia would be very valuable for clinical and epidemiological investigations.

Study supported by a grant of the Agence Nationale de Recherches sur le SIDA (ANRS).

\section{REFERENCES}

Challier S., Brown S., Ombrouck C., Desportes-livage I., De NAY D. \& Gentilini M. Flow cytometry as a possible method of isolation of spores of the microsporidian Enterocytozoon bieneusi. Journal of Eukaryotic Microbiology, 1994, 41, 27S.

De Girolami P.C., Erzatty C.R., Desai G., McCullough A., Asmuth D., Wanke C. \& Federman M. Diagnosis of intestinal microsporidiosis by examination of stool and duodenal aspirate with Weber's modified trichrome and Uvitex 2B stains. Journal of Clinical Microbiology, 1995, 33, 805810 .

Desportes I., Le Charpentier Y., Galian A., Bernard F., Cochand-Priollet B., Lavergne A., Ravisse P. \& ModiGLIANI R. Occurrence of a new microsporidian: Enterocytozoon bieneusi n.g., n. sp. in the enterocytes of a human patient with AIDS. Journal of Protozoology, 1995, 32, 250254.

Fedorko D.P., Nelson N.A. \& CARTwright C.P. Identification of microsporidia in stool specimens by using PCR and restriction endonucleases. Journal of Clinical Microbiology, 1995, 33, 1739-1741.
Hartskeerl R.A., Van Gool T., Schuitema A.R.J., Didier E.S. \& TeRPSTRA W.J. Genetic and immunological characterization of the microsporidian Septata intestinalis Cali, Kotler \& Orenstein, 1993: reclassification to Encephalitozoon intestinalis. Parasitology, 1995, 110, 277-285

Weiss L.M., Zhu X., Cali A., Tanowitz H.B. \& Wittner M. Utility of microsporidian rRNA in diagnosis and phylogeny: a review. Folia Parasitologica, 1994, 41, 81-90.

Reçu le 29 décembre 1995 Accepté le 3 janvier 1996 